\title{
Factors Affecting the Infection of Fruit of Vitis vinifera by the Bitter Rot Pathogen Greeneria uvicola
}

\author{
J. M. Longland and T. B. Sutton
}

Former Graduate Research Assistant and Professor, Department of Plant Pathology, North Carolina State University, Raleigh 27695. Accepted for publication 29 January 2008.

\begin{abstract}
Longland, J. M., and Sutton, T. B. 2008. Factors affecting the infection of fruit of Vitis vinifera by the bitter rot pathogen Greeneria uvicola. Phytopathology 98:580-584.

Bitter rot, caused by the fungus Greeneria uvicola, is one of the most important fruit rot diseases that threaten the burgeoning winegrape (Vitis vinifera) industry in the southeastern United States. Epidemiological studies were conducted to examine the period of fruit susceptibility of $V$. vinifera to G. uvicola, influence of temperature and duration of wetness on infection, and relative susceptibility of cultivars to bitter rot. In field studies, susceptibility of Merlot, Chardonnay, and Cabernet Franc fruit

2 weeks before véraison in 2004 . When detached $V$. vinifera fruit were inoculated and incubated at $14,22,26$, and $30^{\circ} \mathrm{C}$ for $6,12,18$ or $24 \mathrm{~h}$ of wetness, 22.4 to $24.6^{\circ} \mathrm{C}$ and 6 or $12 \mathrm{~h}$ of wetness were the optimal conditions for infection of fruit by $G$. uvicola. The relative susceptibility of 38 cultivars and selections, including $23 \mathrm{~V}$. vinifera cultivars and five FrenchAmerican hybrids, was determined in a detached fruit inoculation assay. A wide range in susceptibility was observed among the cultivars and selections. Fruit of cultivars of V. vinifera were significantly more susceptible than French-American hybrids. Isolates of G. uvicola differed in aggressiveness when tested on cv. Chardonnay.
\end{abstract} increased from bloom until véraison in 2003 and from bloom until
Additional keywords: grapes, Melanconium fuligineum.
Bitter rot of grape, caused by the fungus Greeneria uvicola (Berk. \& M. A. Curtis) Punith. (syn. Melanconium fuligineum (Scribn. \& Viala) Cavara), attacks many Vitis spp., including Vitis vinifera, V. labrusana, and Muscadina rotundifolia (=V. rotundifolia). The disease occurs in the eastern United States and the grape-growing regions of at least 10 other countries $(16,18,19)$. G. uvicola invades pedicels in the spring and remains latent until the fruit begin to ripen (10). It then invades the fruit and symptoms are expressed as olive or brown lesions that develop into a soft rot of the ripening fruit. Yields have been reduced by as much as $30 \%$ in North Carolina $(2,13)$ and up to $50 \%$ in areas of the world where the disease is severe (1).

Literature on bitter rot and the causal organism is scant and outdated. Early research focused only on its identification and control $(2,3,6,9,11,12)$. Programs for the management of bitter rot based on these studies have been most effective when sanitation measures and canopy management are combined with applications of protectant fungicides. To maintain disease control, these fungicides must be applied every 10 to 14 days from bloom to harvest. Because infections by G. uvicola can remain latent until late in the season (8), novice growers may decide against additional fungicide applications on the symptom-free fruit in anticipation of harvest, resulting in disastrous late-season losses to bitter rot. Conversely, more experienced growers may seek to avoid losses by harvesting early, before the sugar and acidity balance is optimum.

Management decisions such as the timing of fungicide applications could be improved by a better understanding of the biology and epidemiology of the disease. Unfortunately, the few epidemiological studies that have been conducted have been primarily on grape species other than $V$. vinifera $(5,7,8)$, which is of most

Corresponding author: T. B. Sutton; E-mail address: turner_sutton@ncsu.edu

doi:10.1094/PHYTO-98-5-0580

(c) 2008 The American Phytopathological Society importance to the wine industry worldwide. Additionally, studies on the susceptibility of $V$. vinifera to bitter rot used cultivars popular in countries other than the United States $(3,6,9,11,12)$.

Consequently, the objective of this study was to better understand the epidemiology of bitter rot in winegrapes by (i) distinguishing the period of fruit susceptibility in $V$. vinifera, (ii) determining the influence of temperature and duration of wetness on infection of $V$. vinifera fruit, and (iii) characterizing the relative susceptibility of winegrape cultivars to G. uvicola.

\section{MATERIALS AND METHODS}

Period of fruit susceptibility in $\boldsymbol{V}$. vinifera. Field studies were conducted in 2003 and 2004 in V. vinifera cvs. Chardonnay and Cabernet Franc vines in Rockingham County, NC, and in V. vinifera cv. Merlot vines in Alamance County, NC. Fruit were atomized biweekly starting from bloom until 2 weeks before harvest. Inoculum was a conidial suspension $\left(10^{5}\right.$ spores $\left./ \mathrm{ml}\right)$ of $G$. uvicola isolate WB5, which was obtained from Chardonnay fruit in Forsyth County, NC, in 2002. Chardonnay and Merlot were inoculated six times each field season; however, due to differences in cultivar ripening, Cabernet Franc was inoculated seven times in both seasons. Five intact clusters were arbitrarily selected for each of four replications for every inoculation date, inoculated in the late afternoon, and sealed in plastic bags. The insides of the plastic bags were atomized with sterile distilled water before sealing them to ensure that free moisture was maintained on the fruit surface overnight. In 2003, the grower cane pruned some vines of Merlot; consequently, there were only two replications on each inoculation date that year. Leaf wetness and temperature were monitored overnight inside one inoculation bag with Watchdog Leaf Wetness and Temperature Loggers (Spectrum Technologies, Inc., Plainfield, IL) for every inoculation date in both vineyards in 2003 and 2004. Disease incidence was evaluated at harvest by counting the number of symptomatic berries and total number of berries per cluster. Fruit were harvested at $\geq 18^{\circ}$ Brix on 25 August 2003 and 18 August 2004 for Chardonnay, on 3 Sep- 
tember 2003 and 27 August 2004 for Cabernet Franc, and on 20 August 2003 and 12 August 2004 for Merlot.

An analysis of variance (ANOVA) was conducted using the SAS general linear models procedure (PROC GLM, version 8.0; SAS Institute, Cary, NC) to determine effects of year, inoculation timing, and their interaction on disease incidence, or percentage of symptomatic berries per cluster at harvest. Separation of means was achieved using the Waller-Duncan $k$-ratio $t$ test with $\mathrm{K}$ ratio $=$ 100. The three cultivars were analyzed separately due to the differences in location and experimental design.

Influence of temperature and duration of wetness on infection. Clusters of $V$. vinifera Chardonnay, Cabernet Franc, and Cabernet Sauvignon were harvested at $\geq 18^{\circ}$ Brix, and the fruit were prepared and inoculated using a detached fruit assay. Briefly, fruit were surface disinfested with $0.525 \% \mathrm{NaOCl}$ for $30 \mathrm{~s}$, rinsed with distilled water, and allowed to dry overnight. Individual fruit were clipped at the pedicel to avoid injury and placed on mesh racks in plastic moisture chambers. Detached fruit were atomized with a conidial suspension $\left(10^{5} \mathrm{spores} / \mathrm{ml}\right)$ of an isolate obtained from Chardonnay fruit in Forsyth County, NC, in 2002 and subjected to the treatments described below. The moisture chambers were maintained free of moisture on the fruit surface for the duration of the experiment.

The experimental design was a split plot, with the whole-plot factor of temperature at levels of $14,18,22,26$, and $30^{\circ} \mathrm{C}$ in growth chambers and a subplot factor of duration of wetness at levels of $6,12,18$, and $24 \mathrm{~h}$. There were three replications of 10 fruit per temperature and wetness combination, and the study was repeated three times for each cultivar. After completion of each wetting duration, further infection was stopped by immersing fruit in $0.525 \% \mathrm{NaOCl}$ for $30 \mathrm{~s}$. Fruit then were rinsed with distilled water, allowed to dry, and incubated at $26^{\circ} \mathrm{C}$ under continuous light on mesh racks in sealed, dry plastic chambers. Disease severity was evaluated 9 to 10 days later using the following scale: $0=$ no infection and $1=1$ to $5,2=6$ to $15,3=16$ to 50 , and $4 \geq 51 \%$ fruit surface with visible symptoms.

The median disease severity was obtained for each replication (i.e., 10 fruit for each temperature and wetness combination). Because an ordinal scale was used to estimate disease severity, the analysis was conducted nonparametrically using PROC RANK and PROC GLM in SAS to estimate the relative marginal effects and ANOVA-type statistic (14). The optimum temperature for infection for each wetting duration was estimated by fitting a quadratic equation to the relative marginal effects for all temperatures tested (severity $=b 0+b 1$ [temperature] $+b 2$ [temperature $\left.{ }^{2}\right]$ ) and solving the following equation: maximum severity $=(-b 1 / 2 b 2)$, where $b 1$ and $b 2$ are the coefficients for the linear and quadratic terms, respectively.

Relative susceptibility of cultivars to bitter rot. Fruit of 38 grape cultivars and selections in total were harvested at $\geq 16^{\circ}$ Brix in 2003 and 2004. Fruit were prepared for the test as described for the detached fruit assay described above. For each of four clusters per cultivar or selection, 20 detached fruit were atomized with a conidial suspension $\left(10^{5}\right.$ spores $\left./ \mathrm{ml}\right)$ of isolate WB5. Fruit were then incubated at $26^{\circ} \mathrm{C}$ under continuous light for 7 days before disease severity was evaluated using the scale above.

Inoculations of each cultivar or selection was repeated two times during the study with the exception of $V$. vinifera Cabernet Franc, which was repeated three times, and the following cultivars that were inoculated only once due to lack of availability: $V$. vinifera cvs. Riesling, Sangiovese, JB97-8-0-7, Petite Sirah, JB96-147-27, Semillon, Barbera, JB96-14-7-12, Perlette, JB94-13-2-26, JB97-8-6-54, and Touriga Nacional; and V. labruscana cv. Sunbelt.

Disease severity was analyzed nonparametrically using PROC RANK and PROC MIXED in SAS to estimate the relative treatment effects and ANOVA-type statistic (14).

Variation in aggressiveness among isolates from $\boldsymbol{V}$. vinifera and $M$. rotundifolia. Ten isolates of G. uvicola were selected for studying variation among isolates. Four isolates, designated as HCMD1, HCMD5, WB4, and WB5, were obtained from V. vinifera fruit, whereas five isolates, designated as HCRS1, WC3, WC5, $\mathrm{BC} 2$, and $\mathrm{MS} 2$, were obtained from $M$. rotundifolia fruit. Isolate $\mathrm{SH}$ was obtained from the French-American hybrid Chambourcin.

Fruit of $V$. vinifera Chardonnay were harvested at $\approx 19^{\circ} \mathrm{Brix}$ from vines in Rockingham and Orange Counties, NC. Fruit were prepared for the test as described above. For each isolate, 10 detached fruit from each of four Chardonnay clusters were selected arbitrarily and atomized with a conidial suspension $\left(10^{5} \mathrm{spores} / \mathrm{ml}\right)$. Ten fruit from each of four clusters also were included in the study as a noninoculated control. The fruit then were incubated in growth chambers at $26^{\circ} \mathrm{C}$ under continuous light for 7 days before disease severity was evaluated.

Disease severity was evaluated using the following scale: $0=$ no infection and $1=1$ to $5,2=6$ to $15,3=16$ to 50 , and $4 \geq 51 \%$ fruit surface with visible symptoms. Presence of acervuli and secondary contaminants also were noted. The study was repeated two times.

Disease severity was analyzed nonparametrically using PROC RANK and PROC MIXED in SAS to estimate the relative treatment effects and ANOVA-type statistic (14). The effect of source host species was examined using contrast statements.

\section{RESULTS}

Period of fruit susceptibility in $\boldsymbol{V}$. vinifera. When data from both years were combined, there were strong interactions for year-inoculation date, with $P$ values of $0.0024,0.0001$, and 0.0011 for Chardonnay, Cabernet Franc, and Merlot, respectively. Therefore, data for each cultivar were analyzed separately for each year.

Inoculation date significantly affected disease incidence in Chardonnay fruit in $2003(P=0.0472)$ and $2004(P<0.0001)$. The susceptibility of Chardonnay fruit increased from bloom until véraison (week 10) in 2003 and from bloom until 2 weeks before véraison (week 10) in 2004 (Fig. 1). In 2004, disease incidence was significantly higher 6 to 8 weeks after bloom than at any other time during the season. Post-véraison inoculations were not performed either year because fruit ripened quickly and were ready to harvest 2 weeks after the inoculation at véraison.

Similar results were observed in Cabernet Franc, where inoculation date was significant in $2003(P<0.0001)$ and $2004(P<$ $0.0001)$. Following inoculation, the highest incidence of bitter rot infection occurred 8 to 10 weeks and 4 to 6 weeks after bloom in 2003 and 2004, respectively, and declined thereafter (Fig. 1). Véraison occurred on week 10.

Fruit of Merlot increased in susceptibility to bitter rot from bloom until véraison (week 8) in 2003 and until 2 weeks before véraison (week 8) in 2004 (Fig. 1). Main effects of inoculation date were significant in both $2003(P=0.0021)$ and $2004(P=$ $0.0003)$. Fruit infection of Merlot was the highest when clusters were inoculated 6 to 10 weeks and 4 to 8 weeks after bloom in 2003 and 2004, respectively.

Data for all cultivars also were examined after arcsine-square root transformation, and the subsequent analysis yielded similar results.

Temperatures in the inoculation bags in the Alamance County vineyard were $22.3 \pm 5^{\circ} \mathrm{C}$ (standard deviation) with $9 \mathrm{~h}$ of wetness in 2003 and $24.8 \pm 5^{\circ} \mathrm{C}$ with $14 \mathrm{~h}$ of wetness in 2004 . Temperatures in the inoculation bags in the Rockingham County vineyard were $23.5 \pm 5^{\circ} \mathrm{C}$ in 2003 and $23.7 \pm 4^{\circ} \mathrm{C}$ in 2004 , with $15 \mathrm{~h}$ of wetness in both years. An exception was the bloom inoculation in 2003 , with an average temperature of $14.7 \pm 4^{\circ} \mathrm{C}$ and $11 \mathrm{~h}$ of wetness. Temperature and leaf wetness data were missing for both vineyards for the inoculation 2 weeks after bloom in 2004 because bags containing the sensors leaked during heavy rains flooding the sensors. 


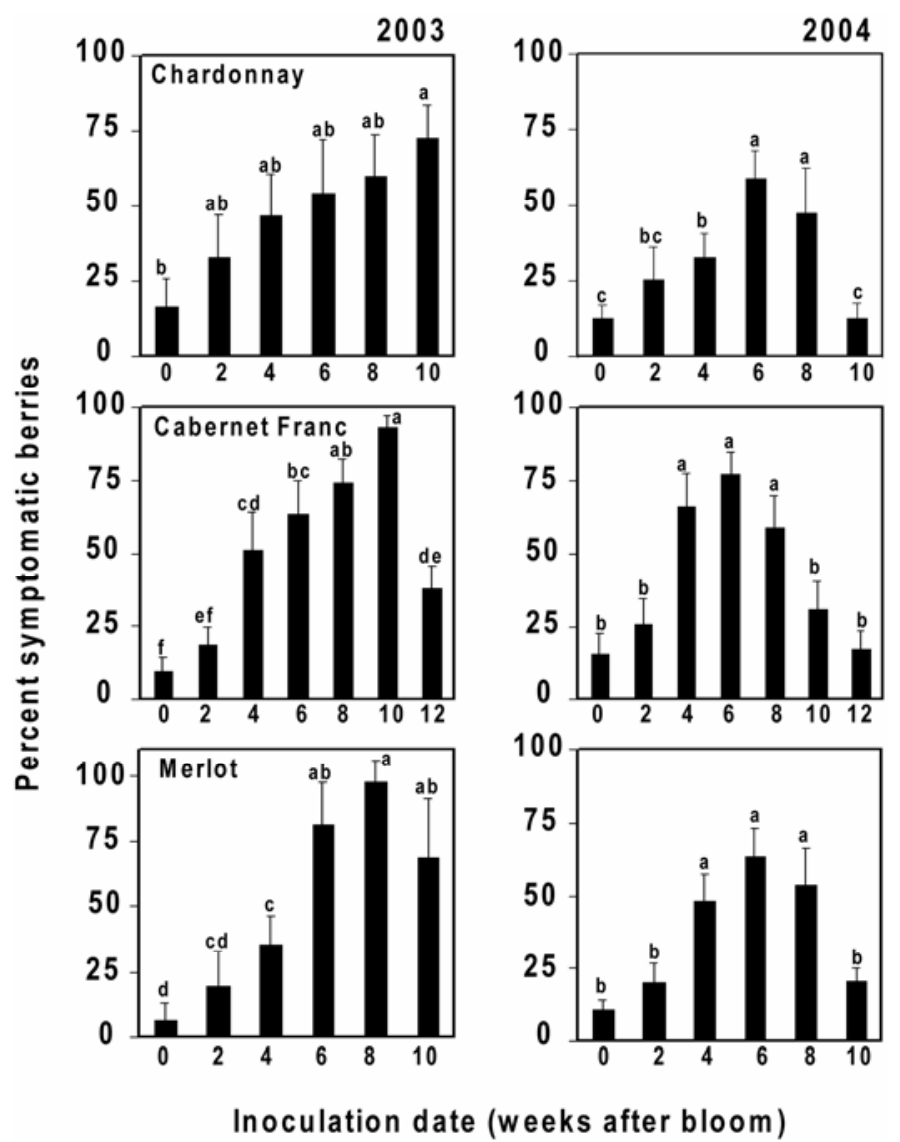

Fig. 1. Relationship between bitter rot (caused by Greeneria uvicola) incidence and inoculation date in 2003 and 2004 for cvs. Chardonnay, Cabernet Franc, and Merlot. Closing and véraison occurred at 4 and 10 weeks after bloom, respectively, for both Chardonnay and Cabernet Franc. Closing and véraison occurred at 4 and 8 weeks after bloom, respectively, for Merlot. Each column represents the mean disease incidence at harvest for a whole vine or cordon $(n=4)$ except for Merlot in $2003(n=2)$. Means sharing a common letter are not significantly different $(P \leq 0.05)$ as determined by the WallerDuncan $k$-ratio $t$ test. Error bars represent standard error.

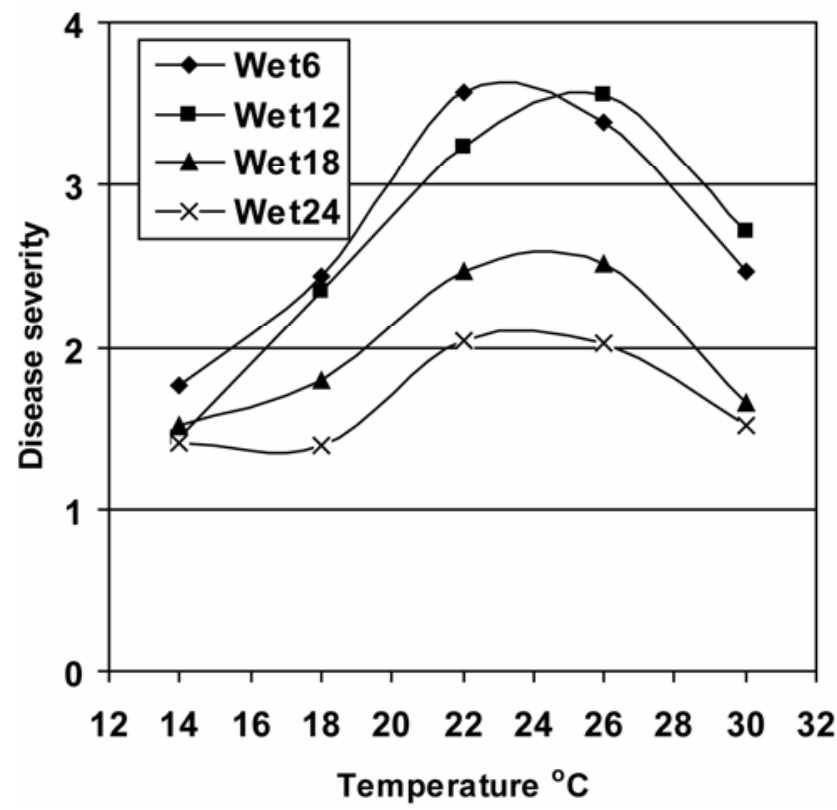

Fig. 2. Relationship between disease (caused by Greeneria uvicola) severity, temperature $\left(14,18,22,26\right.$, and $\left.30^{\circ} \mathrm{C}\right)$, and duration of wetness $(6,12,18$, or $24 \mathrm{~h}$ ) on bitter rot infection in detached Vitis vinifera fruit. Disease severity was evaluated 9 to 10 days after inoculation, using the following scale: $0=$ no infection and $1=1$ to $5,2=6$ to $15,3=16$ to 50 , and $4=>51 \%$ fruit surface with visible symptoms.
Influence of temperature and duration of wetness on infection. When data from all three cultivars were combined, the main effects of temperature and duration of wetness were significant $(P<0.0001)$. Neither the main effect of cultivar $(P=0.9534)$ nor its interactions with temperature $(P=0.1938)$ or duration of wetness $(P=0.4391)$ was significant in this assay. The interaction of temperature-duration of wetness was significant $(P=0.0427)$; consequently, the effect of temperature during each wetting duration was examined separately (Fig. 2). Overall, 6 or $12 \mathrm{~h}$ of wetting was more conducive to infection than 18 or $24 \mathrm{~h}$. The predicted optimum temperature for fruit infection for the four wetting durations tested ranged from 22.4 to $24.6^{\circ} \mathrm{C}$ (mean = $23.3^{\circ} \mathrm{C}$ ).

Relative susceptibility of cultivars to bitter rot. A wide range of susceptibility was observed among the cultivars and selections included in the study (Table 1). The species main effect on disease severity was significant $(P<0.0001)$. Fruit of $V$. vinifera $(n=$ $23)$ were significantly more susceptible to bitter $\operatorname{rot}(P<0.0001)$ than French-American hybrids $(n=5)$. Cultivars Petit Sirah, Petit Verdot, Roussanne, and MissBlanc were among the most susceptible to bitter rot, whereas Arkansas 1271, Chardonel, Cynthiana, Semillon, and selection JB96-14-7-27 were among the most resistant. The inoculated fruit of $V$. aestivalis Cynthiana remained free of bitter rot symptoms for up to 14 days at $26^{\circ} \mathrm{C}$. Secondary

TABLE 1. Median mean rank and relative treatment effects along with $95 \%$ confidence intervals $(\mathrm{CI})$ for bitter rot severity ratings in grape cultivars and selections in 2003 and 2004

\begin{tabular}{|c|c|c|c|c|}
\hline $\begin{array}{l}\text { Cultivar or } \\
\text { selection }\end{array}$ & Median $^{\mathrm{a}}$ & $\begin{array}{c}\text { Mean } \\
\text { rank }\end{array}$ & $\begin{array}{c}\text { Relative } \\
\text { treatment } \\
\text { effect }\end{array}$ & $\begin{array}{c}95 \% \mathrm{CI} \text { for } \\
\text { relative } \\
\text { treatment effects }\end{array}$ \\
\hline Arkansas 1271 & 0.0 & 39.0 & 1.60 & $0.18,0.23$ \\
\hline Chardonel & 0.0 & 39.0 & 1.60 & $0.18,0.23$ \\
\hline Cynthiana & 0.0 & 39.0 & 1.60 & $0.18,0.23$ \\
\hline JB96-14-7-27b & 0.0 & 39.0 & 1.60 & $0.18,0.23$ \\
\hline Semillon $^{\mathrm{b}}$ & 0.0 & 39.0 & 1.60 & $0.18,0.23$ \\
\hline Chambourcin & 0.0 & 46.1 & 1.90 & $0.18,0.32$ \\
\hline Sauvignon Blanc & 0.0 & 51.5 & 2.13 & $0.16,0.41$ \\
\hline Vidal Blanc & 0.0 & 55.4 & 2.29 & $0.15,0.47$ \\
\hline Riesling $^{\mathrm{b}}$ & 0.0 & 57.7 & 2.38 & $0.15,0.51$ \\
\hline Rkatsiteli & 0.0 & 57.7 & 2.38 & $0.20,0.43$ \\
\hline Tempranillo & 3.5 & 60.8 & 2.51 & $0.19,0.47$ \\
\hline Barbera $^{b}$ & 0.0 & 64.0 & 2.65 & $0.14,0.61$ \\
\hline Charbono & 0.3 & 64.8 & 2.68 & $0.23,0.46$ \\
\hline Merlot & 0.0 & 64.8 & 2.68 & $0.19,0.52$ \\
\hline Traminette & 0.3 & 64.8 & 2.68 & $0.23,0.46$ \\
\hline JB86-11-94 & 2.5 & 67.2 & 2.36 & $0.19,0.43$ \\
\hline Sunbelt $^{\mathrm{b}}$ & 0.5 & 78.2 & 3.24 & $0.22,0.63$ \\
\hline Seyval & 0.8 & 84.3 & 3.49 & $0.29,0.60$ \\
\hline Cabernet Sauvignon & 1.0 & 84.7 & 3.51 & $0.30,0.59$ \\
\hline JB96-14-7-12b & 1.0 & 94.0 & 3.90 & $0.41,0.57$ \\
\hline Cabernet Franc & 2.0 & 97.1 & 4.02 & $0.39,0.62$ \\
\hline Perlette $^{b}$ & 3.0 & 116.5 & 4.83 & $0.22,0.89$ \\
\hline Sangiovese ${ }^{b}$ & 1.0 & 116.5 & 4.83 & $0.31,0.84$ \\
\hline $\mathrm{NC74C04482}$ & 2.0 & 123.3 & 5.12 & $0.51,0.75$ \\
\hline Viognier & 3.0 & 125.0 & 5.19 & $0.44,0.81$ \\
\hline JB94-13-2-26 & 2.5 & 125.8 & 5.22 & $0.58,0.72$ \\
\hline JB97-8-0-7b & 4.0 & 128.3 & 5.33 & $0.21,0.93$ \\
\hline Chardonnay & 3.3 & 130.9 & 5.43 & $0.45,0.84$ \\
\hline Syrah & 3.5 & 138.8 & 5.76 & $0.47,0.88$ \\
\hline Touriga Nacional $^{\mathrm{b}}$ & 3.5 & 139.0 & 5.77 & $0.45,0.89$ \\
\hline JB97-8-6-54 ${ }^{\mathrm{b}}$ & 0.0 & 141.7 & 5.88 & $0.55,0.86$ \\
\hline Tinta Cao & 3.8 & 151.3 & 6.28 & $0.66,0.87$ \\
\hline Mourvedre & 3.8 & 155.3 & 6.45 & $0.71,0.88$ \\
\hline Tannat & 3.8 & 155.3 & 6.45 & $0.71,0.88$ \\
\hline MissBlanc & 4.0 & 161.2 & 6.69 & $0.75,0.90$ \\
\hline Roussanne & 4.0 & 167.1 & 6.94 & $0.79,0.92$ \\
\hline Petit Verdot & 4.0 & 169.0 & 7.02 & $0.83,0.91$ \\
\hline Petit Sirah ${ }^{\mathrm{b}}$ & 4.0 & 173.0 & 7.19 & $0.87,0.92$ \\
\hline
\end{tabular}

a Disease severity was evaluated 7 days after inoculation, using the following scale: $0=$ no infection and $1=1$ to $5,2=6$ to $15,3=16$ to 50 , and $4=$ $>51 \%$ fruit surface with visible symptoms.

b Based on inoculations in 2004 only. 
contamination in the noninoculated controls of each cultivar or selection was less than 5\%, except in selection JB97-8-6-54 and one replication of selection NC74CO4482, where $\approx 20 \%$ of the fruit were contaminated. However, any infections by G. uvicola were still visible on contaminated fruit.

Variation in aggressiveness among isolates from $V$. vinifera and $\boldsymbol{V}$. rotundifolia. Isolates of $G$. uvicola differed in aggressiveness when tested on cv. Chardonnay $(P<0.0001)$. Isolates obtained from a $V$. vinifera Cabernet Franc vineyard were the most aggressive (Table 2). Disease severity on the Chardonnay fruit inoculated with isolates collected from $V$. vinifera was significantly higher than with isolates collected from $M$. rotundifolia $(P=0.0093)$. The isolate obtained from the French-American hybrid Chambourcin was less aggressive than isolates obtained from $V$. vinifera $(P=0.0001)$ or $M$. rotundifolia $(P=0.0001)$.

\section{DISCUSSION}

Fruit of V. vinifera Chardonnay, Cabernet Franc, and Merlot were susceptible to latent infection by G. uvicola from bloom until harvest, though they were most susceptible just prior to and during véraison. Previous studies with other Vitis spp. $(5,13)$ found that fruit were susceptible prior to véraison; these studies did not continue beyond that stage. In contrast to our results, recently, Steele et al. (15) found that fruit of Cabernet Sauvignon were most susceptible to infection by $G$. uvicola after véraison. We did not observe any symptoms until just before harvest. Previous work has suggested that symptom expression occurs when soluble solids increase (5). This differs from black rot, caused by Guignardia bidwellii, where fruit are most susceptible 3 to 5 weeks after bloom and decrease in susceptibility after 6 to 7 weeks postbloom (4).

The inoculated $V$. vinifera fruit were not russetted, which also has been associated with early infection of $M$. rotundifolia (8). Likewise, wounding was not a requirement for infection of $V$. vinifera fruit, as previous research in other species suggested $(7,13)$. However, wounding appeared to account for the high incidence of disease in 2003. Excess rainfall led to splitting and cracking of mature fruit, and damage from bird feeding also was observed toward the end of the 2003 season. The Cabernet Franc fruit remained on the vines for 9 days longer than the Chardonnay fruit in 2003 and 2004. This additional exposure to secondary cycles of inoculum may account for the higher incidence in the more resistant Cabernet Franc cultivar at harvest.

The optimal conditions for infection of $V$. vinifera fruit by Greeneria uvicola were temperatures ranging from 22.4 to $24.6^{\circ} \mathrm{C}$ and 6 to $12 \mathrm{~h}$ of wetness. This temperature is slightly lower than previously found when detached fruit of $M$. rotundifolia (13) and $V$. labruscana (5) were inoculated. Disease severity was reduced after 18 and $24 \mathrm{~h}$ of wetting. This may be because antagonists not killed by the disinfesting procedure interfered with infection and colonization of the pedicels. Because infection of fruit can occur with few hours of wetness, it is important for growers to maintain a protectant fungicide program. Environmental conditions are conducive for infection of fruit by G. uvicola throughout the season in areas with climates similar to those in North Carolina.

Isolates of $G$. uvicola obtained from $V$. vinifera were significantly more aggressive on Chardonnay fruit than isolates obtained from $M$. rotundifolia. These results may explain why Clayton (2) stated that losses from bitter rot in $V$. vinifera might be higher than in $M$. rotundifolia. The most aggressive isolates tested were obtained from Cabernet Franc fruit from a vineyard with a chronic bitter rot problem. In our studies, Cabernet Franc was more resistant to bitter rot than Chardonnay. Thus, Vitis spp. and cultivars may select for more aggressive isolates. Further studies to confirm this hypothesis would require examining a larger collection of $G$. uvicola isolates from fields with a history of different levels of disease and possibly characterizing the diversity of the population through molecular analyses.

A wide range of susceptibility to bitter rot was observed among the 38 cultivars and selections tested. Some cultivars and selections were tested in only 1 year; however, we elected to include these data because of the dearth of data on the susceptibility of grape cultivars to G. uvicola. Consequently the rankings of some cultivars or selections may change once additional data are obtained, although many of those tested in only 1 year were very susceptible. Fruit of $V$. vinifera were significantly more susceptible than French-American hybrids, suggesting that interspecific hybrids can inherit increased resistance from their American parent. The susceptibility of cvs. Cabernet Franc, Cabernet Sauvignon, and Seyval to infection by G. uvicola was similar to other fruit rots, whereas Merlot and Sauvignon Blanc were more resistant to infection by the bitter rot pathogen than reported to other fruit rot fungi (17).

Prior to this study, little was known of the susceptibility of winegrape cultivars to infection by $G$. uvicola. The methods used in this study can aid plant breeders in identification and selection of resistant lines. The results of this study also can allow growers to formulate more informed decisions about which cultivars to establish in their vineyard. Even if growers are reluctant to switch from cultivars used to produce popular varietal wines, these results can be used to select grapes planted for blending purposes. The utilization of less susceptible cultivars in combination with good canopy management and regular fungicide applications has the potential to provide reliable control of bitter rot even in production areas with warm, humid climates. In addition, the resistance of $V$. aestivalis Cynthiana to bitter rot and other fruit rots strengthens the case for this cultivar's potential for organic wine production in the southeastern United States.

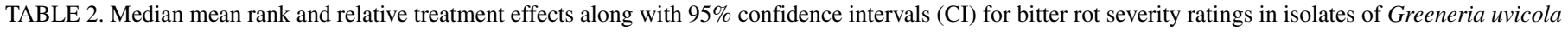

\begin{tabular}{|c|c|c|c|c|c|}
\hline Isolate designation $^{\mathrm{a}}$ & Source host species 'cultivar' & Median $^{\mathrm{b}}$ & Mean rank & $\begin{array}{c}\text { Relative treatment } \\
\text { effect }\end{array}$ & $\begin{array}{c}95 \% \text { CI for relative } \\
\text { treatment effects }\end{array}$ \\
\hline Uninoculated & French-American hybrid 'Chambourcin' & 0.0 & 23.5 & 0.96 & $0.22,0.31$ \\
\hline $\mathrm{SH}$ & Vitis rotundifolia 'Carlos' & 0.0 & 23.5 & 0.96 & $0.22,0.31$ \\
\hline MS2 & V. rotundifolia 'Carlos' & 0.0 & 30.0 & 1.23 & $0.25,0.43$ \\
\hline HCRS1 & V. rotundifolia 'Nesbitt' & 0.0 & 35.3 & 1.45 & $0.28,0.53$ \\
\hline WC3 & V. rotundifolia 'Carlos' & 0.0 & 36.0 & 1.48 & $0.28,0.54$ \\
\hline $\mathrm{BC} 2$ & V. rotundifolia 'Carlos' & 0.0 & 37.4 & 1.54 & $0.29,0.57$ \\
\hline WC5 & V. rotundifolia 'Carlos' & 0.0 & 41.8 & 1.72 & $0.30,0.65$ \\
\hline WB4 & V. vinefera 'Chardonnay' & 1.5 & 54.3 & 2.24 & $0.44,0.75$ \\
\hline WB5 & V. vinefera 'Chardonnay' & 3.0 & 59.4 & 2.45 & $0.48,0.81$ \\
\hline HMD1 & V. vinefera 'Cabernet Franc' & 3.5 & 77.4 & 3.21 & $0.81,0.91$ \\
\hline HMD5 & V. vinefera 'Cabernet Franc' & 4.0 & 70.9 & 2.93 & $0.71,0.86$ \\
\hline
\end{tabular}

a Treatment where fruit was not inoculated was included.

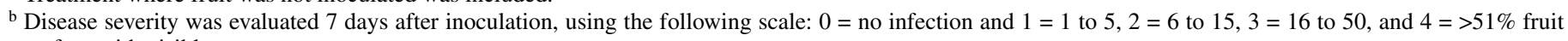
surface with visible symptoms. 
This increased understanding of the period of fruit susceptibility has practical implications for both epidemiology and management of the disease. Because fruit of $V$. vinifera are susceptible from bloom until harvest, fungicide sprays from bloom until véraison are critical, and omission or misapplication of any single spray can result in poor fruit quality and yield loss due to bitter rot. Although rainfall in early summer has been correlated with high incidence at harvest (8), our results suggest that, in production areas with high potential for precipitation near harvest, growers should be especially vigilant in management of the disease prior to exposure to secondary cycles.

\section{ACKNOWLEDGMENTS}

This research was supported in part with funds provided by the Center for Plant Health Science and Technology (CPHST) Plant Protection and Quarantine (PPQ) division of the Animal and Plant Health Inspection Service (APHIS) of the United States Department of Agriculture (USDA). Much of this research was conducted in cooperation with the North Carolina Department of Agriculture and Consumer Services Upper Piedmont Research Station, Reidsville, NC; Iron Gate Vineyards, Mebane, NC; and Bloodworth Nursery, Hillsborough, NC. We thank R. A. Allen, G. Lu, and $\mathrm{O}$. Anas for providing additional valuable assistance.

\section{LITERATURE CITED}

1. Abrahão, E., Regina, M. A., De Souza, S. M. C., and Alvarenga, A. A. 1993. Control of bitter rot and ripe fruit rot in grape plants in the Andradas region, MG, Brazil. Pesqui. Agropecu. Bras. 28:1147-1150.

2. Clayton, C. N. 1975. Diseases of muscadine and bunch grapes in North Carolina and their control. N. C. Agric. Exp. Stn. Bull. 451.

3. Critopoulos, P. D. 1961. Girdling of grapevine canes by Melanconium fuligineum. Phytopathology 51:524-528.

4. Hoffman, L. E., Wilcox, W. F., Gadoury, D. M., and Seem, R. C. 2002. Influence of grape berry age on susceptibility to Guignardia bidwellii and its incubation period length. Phytopathology 92:1068-1076.
5. Kao, C. W., Kuo, K. C., and Leu, L. S. 1990. Symptoms, causal organism, and inoculation of grape bitter rot disease. Plant Prot. Bull. Taichung 32:256-264

6. Kato, K., Toshiyuki, M., Nakagami, K., Hirota, K., and Tomita, I. 1978. Chemical control of grape bitter rot. Res. Bull. Aichi-ken Agric. Res. Cent. Ser. B Hortic. 10:69-75.

7. Kummuang, N., Diehl, S. V., Smith, B. J., and Graves, C. H., Jr. 1996. Muscadine grape berry rot diseases in Mississippi: Disease epidemiology and crop reduction. Plant Dis. 80:244-247.

8. Kummuang, N., Smith, B. J., Diehl, S. V., and Graves, C. H., Jr. 1996. Muscadine grape berry rot diseases in Mississippi: Disease identification and incidence. Plant Dis. 80:238-242.

9. Luttrell, E. S. 1953. Melanconium stem and leaf fleck. Phytopathology 43:347-348.

10. McGrew, J. R. 1988. Bitter rot. Pages 20-22 in: Compendium of Grape Diseases. R. C. Pearson and A. C. Goheen, eds. American Phytopathological Society, St. Paul, MN.

11. Prakash, O., Mishra, B., and Misra A. P. 1974. Greeneria fuliginea Scribner and Viala causing bitter rot of grapes in India. Indian Phytopathol. 27:605-606.

12. Reddy, M. S., and Reddy, K. R. C. 1983. Greeneria fruit rot-an endemic disease of grape in India. Indian Phytopathol. 36:110-114.

13. Ridings, W. H., and Clayton, C. N. 1970. Melanconium fuligineum and the bitter rot disease of grape. Phytopathology 60:1203-1211.

14. Shah, D. A., and Madden, L. V. 2004. Nonparametric analysis of ordinal data in designed factorial experiments. Phytopathology 94:33-43.

15. Steel, C. C., Greer, L. A., and Savocchia, S. 2007. Studies on Colletotrichum acutatum and Greenaria uvicola: Two fungi associated with bunch rot of grapes in sub-tropical Australia. Aust. J. Grape Wine Res. 13:23-29.

16. Sutton, B. C., and Gibson, I. A. S. 1977. Greeneria uvicola. C. M. I. Descr. Pathog. Fungi Bacteriol. 538:1-2.

17. Wolf, T. K., and Poling, E. B. 1995. Pages 1-27 and 53-96 in: The MidAtlantic Winegrape Grower's Guide. North Carolina Cooperative Extension Service, North Carolina State University, Raleigh.

18. Wu, W. S., and Chang, L. 1993. Biological control of grape ripe rot and bitter rot. Plant Pathol. Bull. Taiwan 2:20-25.

19. Yan, R. Q., Zhao, Y. F., Rui, D. M., Li, G. P., and Guo. Q. A. 1998. Integrated management system for the control of grape diseases in the southern part of Jiangsu province. South China Fruits 27:47. 